\title{
GRUNDRISS
}

DER

\section{IRANISCHEN PHILOLOGIE.}

II. BAND. 



\section{GRUNDRISS}

\section{DER \\ IRANISCHEN PHILOLOGIE}

UNTER MITWIRKUNG VON

Chr. Bartholomae, C. H. Ethé, K. F. Geldner.

P. Horn, A. V. W. Jackson, F. Justi, W. Miller, Th. NÖldeke, C. Salemann, A. Socin, F. H. Weissbach und E. W. West

HERAUSGEGEBEN

von

WILH. GEIGER UND ERNST KUHN.

ZWEITER BAND.

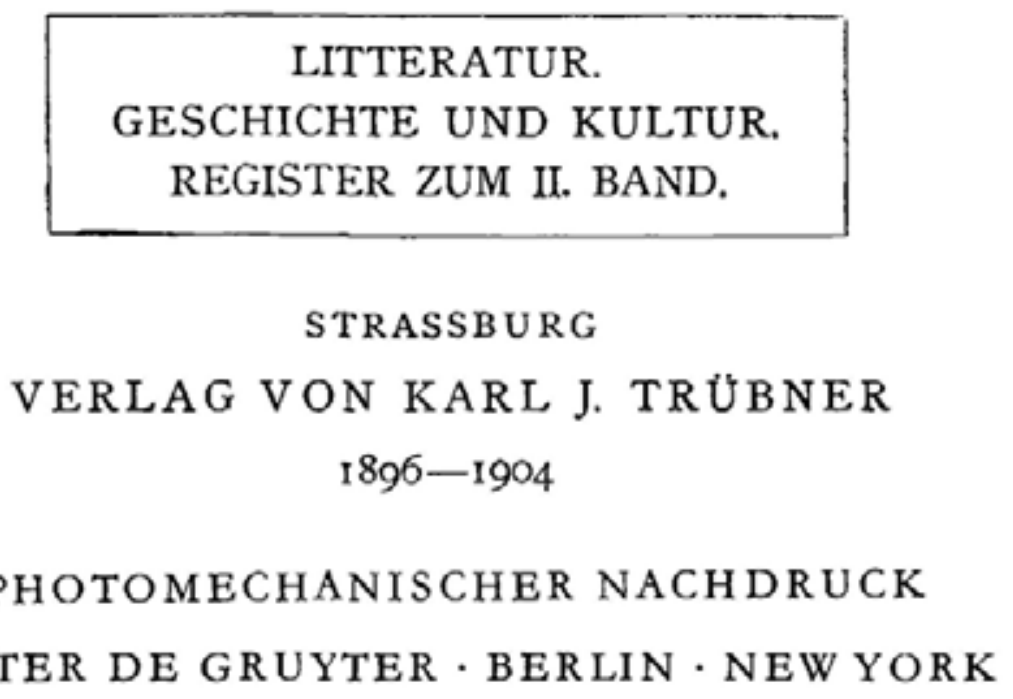


Beim Nachdruck des zweiten Bandes wurde

der Beitrag von Theodor Nöldeke „Das

iranische Nationalepos" durch die 1920

erschienene 2. Auflage ersetzt.

Bd. I u, II: ISBN 3110034918

ISBN 3110024934

(C) $1896-1904 / 74$ by Walter de Gruyter \& Co., vormals G. J. Goscben'sche Verlagshandlung - J. Guttentag,

Verlagsbuchbandlung - Georg Reimer - Karl J. Trübner - Veit \& Comp., Berlin 30

Printed in the Netherlands

Alle Rechte, insbesondere das Recht der Vervielaltigung und Verbreitung, sowie der Ubersetzung,

vorbehalten. Kein Teil des Werkes darf in irgendeiner Form (dureh Photokopic, Mikrofilm oder ein anderes Verfahren) ohne sechriftliche Geachmigung des Verlages reproduriert oder unter Verwendung elektronischer Systeme verarbeitet, vervielfaltigt oder verbreitet werden. 


\section{INHALT.}

\section{ZWEITER ABSCHNITT: LITTERATUR.}

I. Awestalitteratur von K, F, GeLDNER

II. Die altpersischen Inschriften von F. H. WeissBach . . . . . . . . 54

III. Pahlavi Literature by E. W. WeST . . . . . . . . . . . . . . . 75

IV. Das iranische Nationalepos von TH. Nöldeke[2. Auflage] . . . . . . I 30

V. Neupersische Litteratur von Hermann EthE . . . . . . . . . . . 212

\section{DRITTER AbSchnitT: GESCHICHTE UND KULTUR.}

I. Geographie von Iran von Wilhelm Getger . . . . . . . . . . . . 37 I

II. Geschichte Irans von den ältesten Zeiten bis zum Ausgang der Sāsāniden von Ferd. Justi . . . . . . . . . . . . . . . . . . . . . 395

III. Geschichte Irans in islamitischer Zeit von PAUL HoRN . . . . . . . $55 \mathrm{I}$

IV. Nachweisung einer Auswahl von Karten für die geographischen und geschichtlichen Teile des Grundrisses von F. JusrI . . . . . . . . . 605

V. Die iranische Religion von A. V. WilliamS JACKSON . . . . . . . 612 Verzeichnis der wichtigsten Abkürzungen . . . . . . . . . . . 709 Register zum II. Band . . . . . . . . . . . . . . . . . . 711 I. Autorenregister S. 712. II. Sachregister S. 720. Nachtrag 791. 

ZWEITER ABSCHNITT.

\section{LIT TERATUR.}


